\title{
Anion Transporter Binding
}

National Cancer Institute

\section{Source}

National Cancer Institute. Anion Transporter Binding. NCI Thesaurus. Code C40472.

Anion Transporter Binding involves temporary non-covalent interaction of a molecule through intermolecular physical forces of attraction with an anion transporter protein that moves the bound ion carrying a negative charge across a cell membrane with or against a concentration gradient. 